\title{
US detection of renal and ureteral calculi in patients with suspected renal colic
}

\author{
Gianfranco Vallone ${ }^{1}$, Giuseppina Napolitano ${ }^{2}$, Paolo Fonio ${ }^{3}$, Gabriele Antinolfi ${ }^{2}$, Antonio Romeo ${ }^{2}$, Luca Macarini ${ }^{4}$, \\ Eugenio Annibale Genovese ${ }^{5}$, Luca Brunese 2 $^{2 *}$
}

\begin{abstract}
Purpose: The purpose of this study was to determine whether the color Doppler twinkling sign could be considered as an additional diagnostic feature of small renal lithiasis (_5 $\mathrm{mm}$ ).

Methods: 181 patients underwent CT scans performed for other pathologies; the images were also analyzed by a radiologists to identify the incidental presence of renal lithiasis equal to or smaller than $5 \mathrm{~mm}$.

These patients underwent an abdominal ultrasound examination, including grayscale analysis of the kidneys and color Doppler. Lithiasis were divided into three groups, on the basis of the diagnostic agreement provided by CT and gray scale results. Then, the twinkling sign sensitivity was assessed in the three groups.

Results: The twinkling sign was positive in 177 out of 206 lithiasis (86\%) visible on CT, while the grayscale was absolutely positive in 98 out of 206 lithiasis (47.6\%) and doubtful positive in 71 out of 206 lithiasis (31\%).

The twinkling sign was positive in 100\% of absolutely positive and doubtful positive lithiasis on bmode, and in 8 out of 31 lithiasis not visible on b-mode.

Conclusions: In the diagnosis of small renal lithiasis, integrating gray-scale with color Doppler may be the most suitable procedure, because the color-Doppler twinkling sign is able to confirm the doubtful diagnosis of renal lithiasis and to detect some lithiasis that are not visible on b-mode.
\end{abstract}

\section{Introduction}

It is estimated that about $5 \%$ of American women and $12 \%$ of men will develop a renal lithiasis at some time in their life, and these figures are rising [1].

Medium and large renal lithiasis $(>5 \mathrm{~mm})$ can be easily detected with 2D ultrasonography due to the different echogenicity with the adjacent parenchyma and the posterior acoustic shadowing [2].

In the case of small renal lithiasis ( $\left.\_5 \mathrm{~mm}\right)$, differential diagnosis between suspected renal lithiasis and hyperechoic foci caused by other factors (e.g. vascular and/or parenchymal calcifications, clots, arcuate arteries) is difficult $[3,4]$. The identification of an additional sonographic feature of renal lithiasis is therefore important to reduce the number of false negatives and false positives as well as the number of examinations $[5,6]$. The

\footnotetext{
* Correspondence: lucabrunese@libero.it

${ }^{2}$ Department of Health Science, University of Molise, Campobasso, Italy

Full list of author information is available at the end of the article
}

Doppler twinkling sign has often been associated with lithiasis [7-9].

The aim of this study was to investigate whether the Doppler twinkling sign is linked to the presence of small renal lithiasis $\left(\_5 \mathrm{~mm}\right)$.

\section{Patients and methods}

Between April 2004 and February 2007, 181 consecutive patients with various abdominal pathologies (not directly linked to renal lithiasis) were included in our study (109 males and 72 females; age range 36-65, mean age 52). All patients underwent $\mathrm{CT}$, showing at least one renal lithiasis. All patients then underwent US at our department.

The CT scans, performed for other pathologies with a four-detector spiral CT Philips MX8000, were analyzed by a radiologist to identify the incidental presence of renal lithiasis equal to or smaller than $5 \mathrm{~mm}$ [10].

US and color Doppler examinations were performed with GE Logiq 9 (General Electric Company, Milan, Italy), a commercially available real-time US system, equipped with a $1,5-$ to $4.5-\mathrm{MHz}$ convex transducer (4C General

\section{SpringerOpen ${ }^{\circ}$}

(C) 2013 Vallone et al; licensee BioMed Central Ltd. This is an Open Access article distributed under the terms of the Creative Commons Attribution License (http://creativecommons.org/licenses/by/2.0), which permits unrestricted use, distribution, and reproduction in any medium, provided the original work is properly cited. 
Electric Company, Milan, Italy). Two sonographers performed the examinations. They were aware of the number of renal lithiasis but were blinded to their side and location. A different investigator carried out the data analysis.

Each ultrasound examination included a grey-scale and a color Doppler renal examination.

During the US examination, the physician focused on the detection of renal lithiasis, equal to or smaller than $5 \mathrm{~mm}$ [10]. In order to visualize any posterior acoustic shadowing, focal zones were placed at the same depth as or slightly deeper than the lithiasis, with careful control of the grey-scale gain setting. A multicolor map was used during the color Doppler sonography; the color window size was adjusted to include the entire lesion and adjacent tissue. The color Doppler gain was set just below the threshold for color noise in order to eliminate the noise of adjacent soft tissues [11-13].

The sonographic appearance of renal lithiasis was analyzed on the basis of size, echogenicity difference between suspected lithiasis and adjacent tissue and posterior acoustic shadowing. The CT scan determined the size of the lithiasis. The echogenicity difference between the lithiasis and the adjacent tissue was recorded as marked, slight or absent. The posterior acoustic shadowing was recorded as present or absent.

Lithiasis were divided into three groups:

1. Lithiasis that, on grey-scale, provided the same diagnosis of CT (i.e., CT positive and absolutely positive on ultrasound (US), same side and location). Lithiasis showing posterior shadow cone and/or marked echogenicity difference (compared to the surrounding parenchyma) were classified as absolutely positive on US.

2. Lithiasis that on grey-scale raised some diagnostic doubts with comparison to CT (i.e., CT positive and doubtful positives on US, same side and location). Lithiasis showing no posterior shadow cone and slight echogenicity difference (compared to the surrounding parenchyma) were classified as doubtful positives on grey-scale.

3. Both B-mode and CT scan demonstrated identical efficacy in identifying lithiasis (i.e., CT positive but not visible on grey-scale images). Lithiasis classified as not visible on grayscale images had the following characteristics: they were observed on CT in a clear area of the kidney, but did not appear on grey-scale images in the same area as hyperechogenic foci with posterior shadow cone or with at least a minimal echogenicity difference.

CT negative grey-scale positive lithiasis (regardless of diagnostic certainty) were excluded from our study.

All 181 patients with lithiasis underwent a colorDoppler sonography to assess the presence and intensity of the twinkling sign.

The color-Doppler, grey-scale and CT results were compared in order to assess the twinkling sign sensitivity in each of the three groups.

\section{Results}

On abdominal CT scans, 81 selected patients showed 206 renal lithiasis equal to or smaller than $5 \mathrm{~mm}$. The diameter of renal lithiasis ranged from 2.6 to $5.0 \mathrm{~mm}$ (average diameter $4.1 \mathrm{~mm}$ ).

Out of 206 CT positive lithiasis, 98 (47.6\%) were absolutely positive on gray-scale. Out of the 98 lithiasis, 14 were hyperechogenic foci with posterior shadow cone, but with a slight echogenicity difference, 60 showed both posterior shadow cone and a marked echogenicity difference, and 24 showed a marked echogenicity difference without posterior shadow cone. So, the posterior shadow cone appeared 74 out of 98 times, while marked echogenicity difference was detected 84 times.

All 98 lithiasis of this group were twinkling sign positive $(100 \%)$.

Out of 206 CT positive lithiasis, 71 (34.5\%) were greyscale doubtful positive with the following characteristics: hyperechogenic foci, slight echogenicity difference and no posterior shadow cone.

All 71 lithiasis of this group were twinkling sign positive (100\%).

The remaining 37 (18\%) CT positive lithiasis were not visible on grey-scale in the same area they were observed on CT. Out of these 37 lithiasis, 8 were twinkling sign positive.

In total, the twinkling sign was positive in 177 out of 206 lithiasis ( $86 \%$ sensibility) visible on $\mathrm{CT}$, while the greyscale was absolutely positive in 98 out of 206 lithiasis (47.6\%) and doubtful positive in 71 out of 206 lithiasis (31\%).

Results are summarized in Tables 1 and 2.

\section{Discussion}

Medical literature shows that the most valuable echographic parameters for renal lithiasis, i.e. the posterior shadow cone and the hyperechogenic foci with marked echogenicity difference from the surrounding tissue have a low sensitivity compared to the total cases of renal lithiasis. This factor explains why CT is so often required in the diagnosis of suspected renal lithiasis.

The twinkling sign [14] is generated from the 'noise' stemming from rough interfaces composed of sparse reflectors, such as lithiasis or vascular calcifications, which split the sonography beam in a complex unit of waves. This produces a mix of red and blue pixels on color Doppler as turbulent flows [15,16] (Figure 1).

As shown in literature, the twinkling sign can also be associated with vascular and/or parenchymal calcifications $[17,18]$. It is possible to differentiate between these entities: when the twinkling sign is produced by vascular calcifications, it appears near a structure that at the same time produces a pulsing color signal due to the blood flow [19-22]. When the twinkling sign is produced by 
Table 1 Twinkling sign and group of grey-scale examinations

\begin{tabular}{lll}
\hline $\begin{array}{l}\text { Results of grey-scale } \\
\text { examinations }\end{array}$ & $\begin{array}{l}\text { Numbers of } \\
\text { calculi }\end{array}$ & $\begin{array}{l}\text { Twinkling sign } \\
\text { sensitivity }\end{array}$ \\
\hline absolutely positive & 98 & $100 \%(98 / 98)$ \\
doubtful positives & 71 & $100 \%(71 / 71)$ \\
not visible & 37 & $21,62 \%(8 / 37)$ \\
\hline
\end{tabular}

Table 2 Presence and Sensitivity of US features

\begin{tabular}{lll}
\hline US features & $\begin{array}{l}\text { Presence of } \\
\text { the feature }\end{array}$ & Sensitivity\% \\
\hline B-mode marked echogenicity difference & $64 / 206$ & $31,06 \%$ \\
Posterior acoustic shadowing & $74 / 206$ & $35,92 \%$ \\
Twinkling sign & $177 / 206$ & $85,92 \%$ \\
$\begin{array}{l}\text { Combination of posterior acoustic } \\
\text { shadowing and bmode marked }\end{array}$ & $98 / 206$ & $47,57 \%$ \\
echogenicity difference (and/or) & & \\
\hline
\end{tabular}

intraparenchymal calcifications, it differs from lithiasis due to its parenchymal location [23-25].

This study demonstrates that the twinkling sign is often associated with the presence of small renal lithiasis $\left(\_5 \mathrm{~mm}\right)$ and its identification can increase ultrasonography capabilities almost to CT levels. In our study, the twinkling sign was present in 177 (86\%) out of 206 renal lithiasis identified with CT.

In the first group of lithiasis (CT positive and absolutely positive to grey-scale ultrasound, same side and location), the twinkling sign was always positive, proving to be as valuable and sensitive a sign as the other greyscale parameters considered in medical literature. It is very interesting to compare the grey-scale images and the color-Doppler results of the second group of lithiasis (CT positive and doubtful positive on grey-scale images).

In the case of these lithiasis, which are very frequent due to the echostructural complexity of the renal medulla, the grey-scale parameters are not capable of providing a clear diagnosis. CT is required in order to do this. The twinkling sign is $100 \%$ positive in the lithiasis of this group, leading the way to a new diagnostic approach. It provides a new diagnostic tool for ultrasound to be used in those cases (71 out of 206 cases in our study, 34.5\%) where classical ultrasound semeiotics only provide a doubtful diagnosis.

This means that the use of ionizing radiation is not necessary in the case of hyperechogenic foci with slight echogenicity differences and without posterior shadow cones on twinkling sign positive grey-scale images (Figure 2).

As regards the third group of lithiasis (CT positive but not visible on grey-scale ultrasound), the twinkling sign was positive in 8 out of 37 cases (22\% sensitivity) (Figure 3 ). Although this method demonstrates low sensitivity in the detection of this group of lithiasis it is still useful as these lithiasis are not detectable by B-mode. The twinkling sign therefore provides a significant diagnostic advantage compared to grey-scale images, especially if we compare the sensitivity of the two techniques in the diagnosis of lithiasis in this specific group ( $21.6 \%$ vs $0 \%$ ).

Moreover, the color-Doppler must be accurate and rigorous in order to identify the twinkling sign, aiming at finding a scanning plan in which the ultrasound beam is exactly perpendicular to the lithiasis. Only in this specific case does the lithiasis produce the twinkling sign. Identifying the twinkling sign is therefore much more difficult in color-Doppler because for these lithiasis, there are no grey-scale parameters that might raise some doubts and lead the physician to focus on a certain area of the kidney on color-Doppler. False negatives (29 out of 206) on the twinkling signs could be produced by the interference of obesity, intestinal meteorism and lack of cooperation by the patient with the ultrasound technique.

It may thus be inferred that, for a clear diagnosis, the twinkling sign is a much more sensitive parameter (86\%) on the total number of lithiasis compared to the posterior

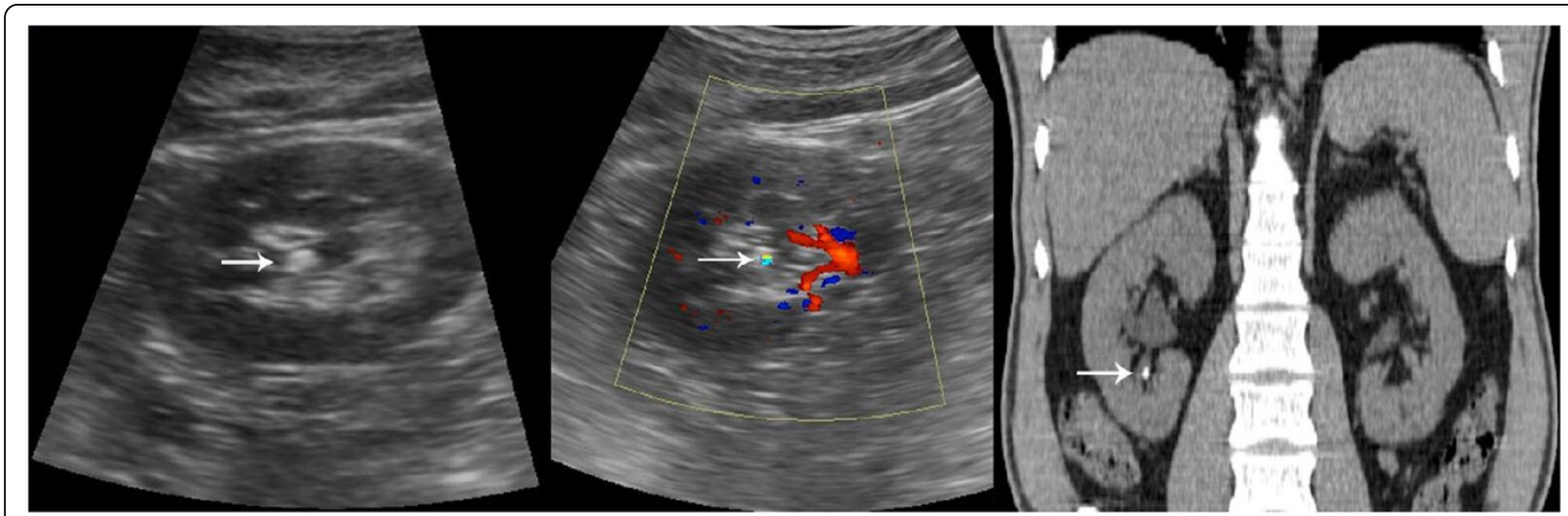

Figure 1 Gray-scale sonogram shows hyperechoic spot with posterior acoustic shadowing. Color Doppler sonogram shows a twinkling sign. A small renal stone. Unenhanced $C T$ confirms the presence of renal stone. 


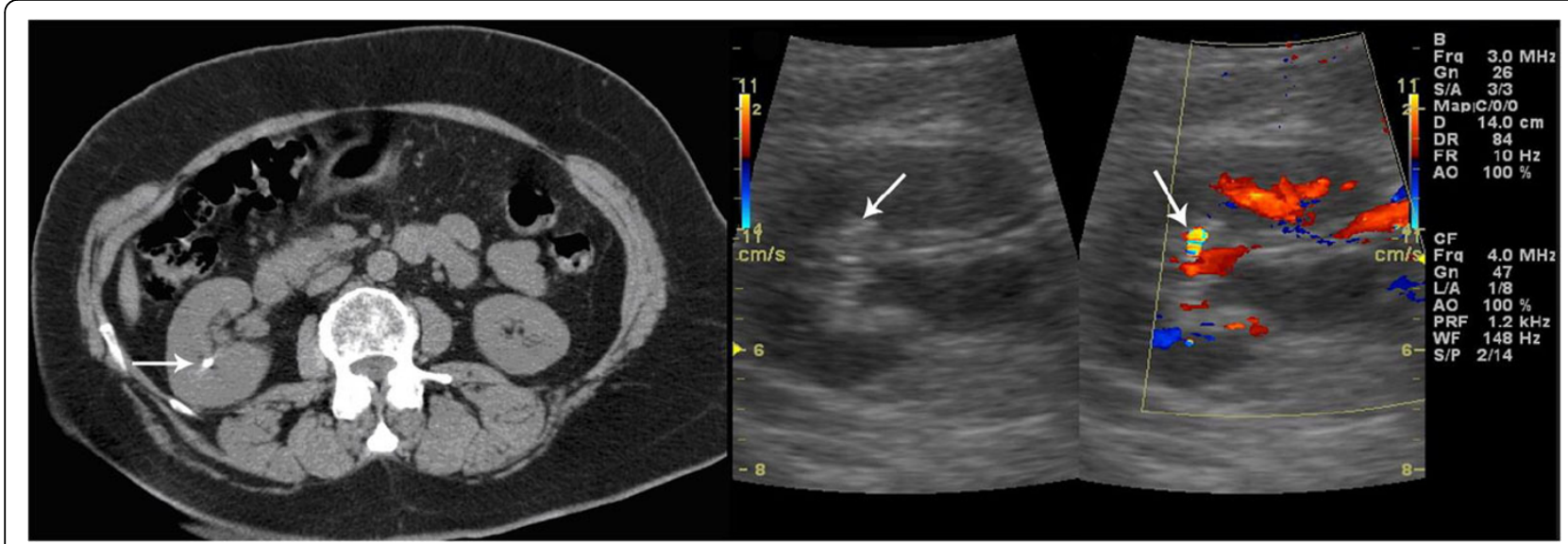

Figure 2 Unenhanced CT confirms the presence of renal stone. Grey-scale sonogram shows small hyperechoic spot without posterior acoustic shadowing. Color Doppler sonogram shows a twinkling sign.

shadow cone (36\%) and to the marked echogenicity difference (31\%), and also compared to both parameters (47.6\%) (Tab.2).

As already mentioned, CT negative, grey-scale positive lithiasis (regardless of diagnostic certainty) were excluded from our study. Lithiasis might be CT negative because of the presence of false positives on grey-scale and, quite seldom, because of sampling mistakes due to CT parameters that were not compatible with the dimensions of the small lithiasis. In our opinion, including this group of lithiasis would imply a loss of objectivity in our study, leading our team to make philosophical speculations on the existence or non-existence of what might appear on the images. For this reason, we decided to focus

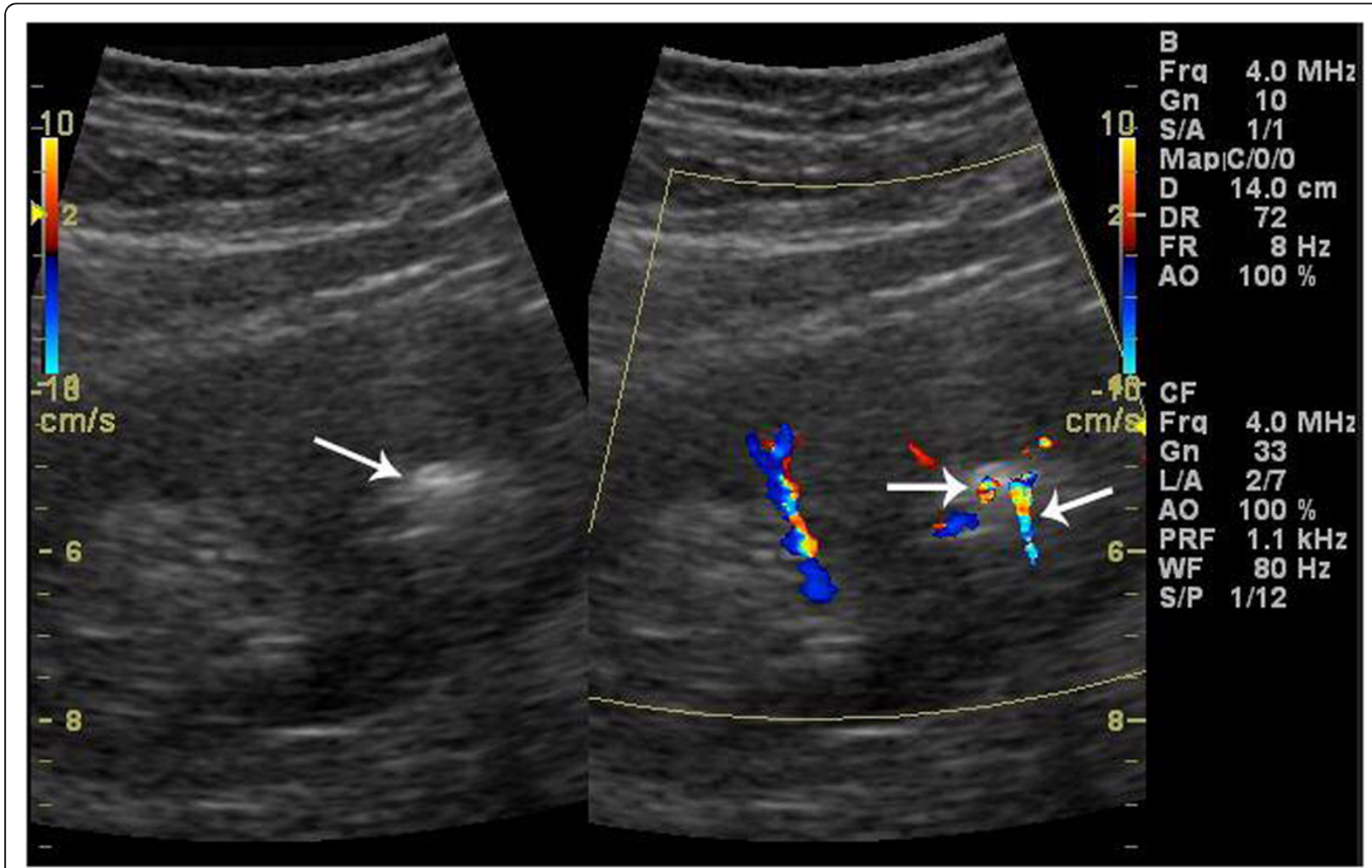

Figure 3 Two small renal stones with calyceal dilatation. Grey-scale sonogram shows only one hyperechoic spot with posterior acoustic shadowing. Color Doppler sonogram reveals two twinkling signs. 
on clearly diagnosed lithiasis, using $\mathrm{CT}$ as selection technique.

\section{Conclusions}

In conclusion, the twinkling sign showed the highest sensitivity in the case of certain or doubtful diagnosis of renal lithiasis on grey-scale. In some cases, the twinkling sign was also able to show the presence of lithiasis when greyscale images were unable even to assume their presence.

We believe that in cases of suspected small renal lithiasis, integrating grey-scale images with color Doppler is the most appropriate procedure in the diagnosis of renal small lithiasis.

\section{Competing interests}

The authors declare that they have no competing interests.

\section{Declarations}

This article has been published as part of Critical Ultrasound Journal Volume 5 Supplement 1, 2013: Topics in emergency abdominal ultrasonography. The full contents of the supplement are available online at http://www. criticalultrasoundjournal.com/supplements/5/S1. Publication of this supplement has been funded by the University of Molise, University of Siena, University of Cagliari, University of Ferrara and University of Turin.

\section{Author details}

${ }^{1}$ Department of Biomorphological and Functional Sciences, University of Naples Federico II, Naples, Italy. ${ }^{2}$ Department of Health Science, University of Molise, Campobasso, Italy. ${ }^{3}$ Institute of Diagnostic and Interventional Radiology, University of Turin , Turin, Italy. ${ }^{4}$ Department of Radiology, University of Foggia, Foggia, Italy. ${ }^{5}$ Department of Radiology, University of Cagliari, Cagliari, Italy.

Published: 15 July 2013

\section{References}

1. Coe FL, Evan A, Worcester E: Kidney stone disease. J Clin Invest 2005, 115(10):2598-608, [Full Text].

2. Middleton WD, Dodds WJ, Lawson $T L$, et al: Renal calculi: sensitivity for detection with US. Radiology 1988, 167(1):239-44, [Full Text].

3. Kane RA, Manco LG: Renal arterial calcification simulating nephrolithiasis on sonography. Am J Roentgenol 1983, 140:101-104, [Full Text].

4. Taylor KJ, Holland S: Doppler US. Part I. Basic principles, instrumentation, and pitfalls. Radiology 1990, 174:297-307, [Full Text].

5. Lee JY, Kim SH, Cho JY, et al: Color and power Doppler twinkling artifacts from urinary stones: clinical observations and phantom studies. Am J Roentgenol 2001, 176:1441-1445, [Full Text].

6. Pinto A, Caranci F, Romano L, Carrafiello G, Fonio P, Brunese L: Learning from errors in radiology: a comprehensive review. Semin Ultrasound $C T$ MR 2012, 33(4):379-82.

7. Aytac SK, Ozcan H: Effect of color Doppler system on the twinkling sign associated with urinary tract calculi. J Clin Ultrasound 1999, 27(8):433-9, [Abstract only].

8. Clayman RV: Characterization of urinary calculi: in vitro study of "twinkling artifact" revealed by color-flow sonography. J Urol 1999, 162(2):632, [Abstract not available].

9. Chelfouh N, Grenier N, Higueret D, et al: Characterization of urinary calculi: in vitro study of "twinkling artifact" revealed by color-flow sonography. Am J Roentgenol 1998, 171:1055-1060, [Full Text].

10. Memarsadeghi $M$, Heinz-Peer $G$, Helbich $\mathrm{TH}$, et al: Unenhanced multidetector row $\mathrm{CT}$ in patients suspected of having urinary stone disease: effect of section width on diagnosis. Radiology 2005, 235(2):530-6, Epub 2005 Mar 9. [Full Text].

11. Kamaya A, Tuthill T, Rubin JM: Twinkling Artifact on Color Doppler Sonography: Dependence on Machine Parameters and Underlying Cause. Am J Roentgenol 2003, 180:215-2221, [Full Text].
12. Kimme-Smith C, Perrella RR, Kaveggia LP: Detection of renal stones with real-time sonography: effect of transducers and scanning parameters. Am J Roentgenol 1991, 157:975-980, [Full Text].

13. Brunese L, Romeo A, lorio S, Napolitano G, Fucili S, Zeppa P, Vallone G, Lombardi G, Bellastella A, Biondi B S, Sodano A: Thyroid B-flow twinkling sign: A new feature of papillary cancer. European Journal of Endocrinology 2008, 159(4):447-451

14. Brunese L, Romeo A, lorio S, Napolitano G, Fucili S, Biondi B, Vallone G, Sodano A: A new marker for diagnosis of thyroid papilary cancer: B-flow twinkling sign. Journal of Ultrasound in Medicine 2008, 27(8):1185-1194.

15. Campbell SC, Cullinan JA, Rubens DJ: Slow Flow or No Flow? Color and Power Doppler US pitfalls in the abdomen and pelvis. RadioGraphics 2004, 24:497-506, [Full Text].

16. Mitchell DG: Color Doppler imaging: principles, limitations, and artifacts. Radiology 1990, 177:1-10, [Full Text].

17. Rebonato A, Vannini E, Giganti M, Volterrani L, Fonio P, Piscioli I, Scialpi M: Small renal oncocytoma $(\leq 4 \mathrm{~cm})$ : enhancement patterns on triphasic spiral computed tomography. Recenti Prog Med 2012, 103(11):477-82.

18. Rebonato $A$, Pierotti $L$, Barberini $F$, Rosi G, Macarini $L$, Scialpi M: Small renal cell carcinoma $(\leq 4 \mathrm{~cm})$ : enhancement patterns on triphasic spiral CT. Recenti Prog Med 2012, 103(11):471-6.

19. Scardapane A, Pagliarulo V, lanora AA, Pagliarulo A, Angelelli G: Contrastenhanced multislice pneumo-CT-cystography in the evaluation of urinary bladder neoplasms. Eur J Radiol 2008, 66(2):246-52.

20. Vitale M, Zeppa P, Esposito I, Esposito S: Infected lesions of diabetic foot Infez Med 2012, 20(Suppl 1):14-9, Review. Italian.

21. Carrafiello G, Laganà D, Mangini M, Cuffari S, Cafaro T, Recaldini C, Genovese E, Fugazzola C: The role of interventional radiology in the management of kidney transplant complications. Radiol Med 2005, 110(3):249-61.

22. Rebonato A, D'Andrea A, Scialpi M: Painless but problematic. Imaging modalities were useful in the diagnosis and treatment of an unusual tumor. Am J Obstet Gynecol 2013, 208(3):237, e1-2.

23. Esposito F, Di Serafino M, Sgambati P, Mercogliano F, Tarantino L Vallone G, Oresta P: Ultrasound contrast media in paediatric patients: is it an off-label use? Regulatory requirements and radiologist's liability. Radiol Med 2012, 117(1):148-59.

24. Scialpi M, Cardone G, Barberini F, Piscioli I, Rotondo A: Renal oncocytoma: misleading diagnosis of benignancy by using angular interface sign at MR imaging. Radiology 2010, 257(2):587-8, author reply 588.

25. Scialpi M, Brunese L, Piscioli I, Rotondo A: Dynamic contrast-enhanced MR imaging for differentiation of renal cell carcinoma subtypes: myth or reality? Radiology 2009, 252(3):929, author reply 930-1.

doi:10.1186/2036-7902-5-S1-S3

Cite this article as: Vallone et al:: US detection of renal and ureteral calculi in patients with suspected renal colic. Critical Ultrasound Journal 2013 5(Suppl 1):S3.

\section{Submit your manuscript to a SpringerOpen ${ }^{\circ}$ journal and benefit from:}

- Convenient online submission

- Rigorous peer review

- Immediate publication on acceptance

- Open access: articles freely available online

- High visibility within the field

- Retaining the copyright to your article

Submit your next manuscript at $>$ springeropen.com 